\title{
Geração de renda: enfoque nas mulheres pobres e divisão sexual do trabalho
}

\section{Income generation: focus on poor women and sexual division of labor}

\author{
Cássia Maria Carloto* \\ Anne Grace Gomes **
}

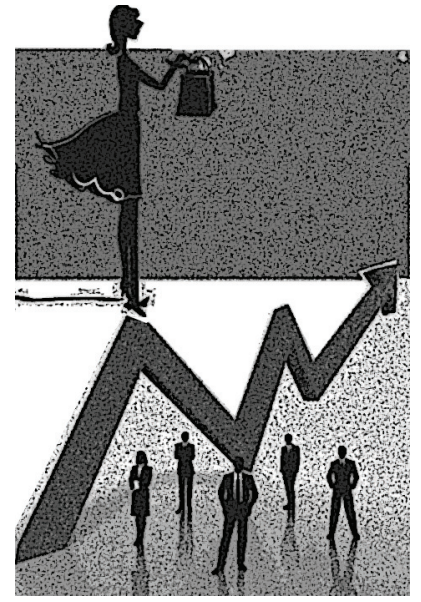

Resumo: Este trabalho apresenta uma discussão a respeito dos projetos de geração de renda voltados para as mulheres pobres. Busca refletir sobre que possibilidades oferecem, enquanto política pública, para a autonomia financeira e a quebra de padrões baseados na tradicional divisão sexual do trabalho ancorada na falsa dicotomia público-privado. Traz também um debate sobre a pobreza entre as mulheres já que a perspectiva desses projetos é aumentar os ganhos da família a partir da focalização nas mulheres.

Palavras-chave: Divisão sexual do trabalho. Geração de renda. Neoliberalismo. Pobreza.

\begin{abstract}
This paper presents a discussion of income-generating projects aimed at poor women. Aims to reflect on what opportunities they offer, while public policy, financial autonomy and the breaking of patterns based on the traditional sexual division of labor rooted in the false dichotomy between public and private. It also brings a debate on poverty among women since the prospect of these projects is to increase earnings from the family focus on women.
\end{abstract}

Keywords: Sexual division of labor. Income generation. Neoliberalism. Poverty.

* Assistente social, doutorado em Serviço Social, docente da Universidade Estadual de Londrina, Departamento de Serviço Social da Universidade Estadual de Londrina/PR, Brasil. E-mail: cmcarloto@gmail.com.

** Assistente social, mestranda em Serviço Social e Política Social do curso de Pós-Graduação em Serviço Social e Política Social, Departamento de Serviço Social da Universidade Estadual de Londrina/PR, Brasil.E-mail: anne.ss@hotmail.com. 


\section{Introdução}

m que medida os projetos de geração de renda, enquanto política
pública pode incidir sobre a estrutura das relações de poder entre os
sexos e sobre a organização do trabalho na perspectiva de gênero? É
partir dessa indagação que nos propomos a levantar algumas questões neste texto. A perspectiva é contribuir no sentido de ampliar o debate da real incorporação de gênero no conteúdo das políticas públicas, mais especificamente àquelas que se referem à geração de renda, já que, o que se observa, é que se usa o termo gênero para designar sua transversalidade nas políticas, mas seu conteúdo crítico é esvaziado ao longo do processo de formulação e execução, principalmente na esfera municipal, onde se operacionalizam tais projetos.

O eixo teórico-metodológico desenvolvido tem como principal categoria de análise a divisão sexual do trabalho.

\section{Relação de gênero e divisão sexual do trabalho}

Pensar o trabalho enquanto prática social sexuada significa dizer que não se trata de uma atividade homogênea ao gênero humano, mas sim de prática que possui características e significados diferenciados no contexto das relações sociais entre os sexos.

Assim como a divisão social do trabalho existe para organizar o conjunto de atividades de produção na sociedade, a divisão sexual do trabalho - que não se trata de uma categoria separada da noção de divisão social e técnica do trabalho - existe para organizar o trabalho de homens e mulheres na estrutura social. Isso equivale dizer que, socialmente, se configura um arranjo de competências e atribuições que pertencem ao gênero feminino, e outro arranjo de funções que pertencem ao gênero masculino.

A definição de divisão sexual do trabalho expressa como categoria as relações de poder entre homens e mulheres, poder que se distribui de forma desigual, conformando historicamente a subordinação feminina e sua invisibilização no processo histórico. De acordo com Kergoat (2003), a divisão sexual do trabalho é a forma de divisão social do trabalho decorrente das relações sociais entre os sexos, adaptadas historicamente e em cada sociedade. 
A autora ainda comenta que é um fator predominante para a sobrevivência da relação entre os sexos. Tem como características a designação prioritária dos homens à esfera produtiva e para as mulheres a esfera reprodutiva e, simultaneamente, a apropriação pelos homens de funções com maior valor social. É importante lembrar que essas duas esferas não são dicotômicas e atuam de forma articuladas para a manutenção do modelo econômico capitalista.

Conforme Kon $(2005$, p. 2), a divisão do trabalho entre homens e mulheres surge na família, "pois desde a economia predominantemente rural ou pré-industrial, homem e mulher desempenhavam dentro da família papéis relevantes distintos enquanto produtores de bens e serviços à sociedade". Ainda que a participação na produção se desse na mesma medida — de formas qualitativamente diferentes - a mulher ainda permanecia a figura central da vida doméstica, responsável pela reprodução da força de trabalho, por meio das tarefas de cuidados e pela procriação. De acordo com Kon $(2005$, p. 2):

A atividade econômica da mulher tem se originado de sua função prioritária de reprodução da força de trabalho, desde que a teoria econômica veio se delineando. Desta função se originam as diferentes formas que tem assumido a subordinação feminina, em distintas sociedades. Dessa maneira, a participação da mulher na produção, a natureza de seu trabalho e a divisão do trabalho entre os sexos são considerados resultados de suas atividades de reprodução, resultado este condicionado também pela natureza dos processos produtivos e pelas exigências de um determinado sistema de crescimento e acumulação que se transforma com o tempo.

As práticas sociais das mulheres estruturaram-se em torno da imagem materna e conjugal, assim como o trabalho feminino teve sua vinculação direta à esfera doméstica, à família e à produção dos cuidados; funções que, na ordem patriarcal, assumem um status inferior na construção da sociedade e, por isso, invisibilizados enquanto atividades de relevância econômica. É importante salientar que os cuidados e a reprodução são reconhecidos enquanto práticas essenciais à existência e à sobrevivência humana. A questão é que se tornou um papel "sexualizado", no qual a mulher apresenta uma habilidade natural, movida pelo afeto e pelo amor, por isso não pode ser elevado à categoria de trabalho ou de atividade fundamental à economia, visto que se trata de algo quase "instintivo". Esta imagem construída do trabalho domés- 
tico segmentou as mulheres a uma esfera invisível, excluindo-as como sujeitos da história.

Os cuidados básicos dispensados no lar são fundamentais para a formação humana, sem os quais seria impossível garantir oferta de força de trabalho. $\mathrm{O}$ trabalho doméstico, desempenhado regularmente pela mulher, ainda que a mesma trabalhe assalariada — e daí decorre o fenômeno da dupla jornada atua como agente de manutenção da vida, e, portanto das condições básicas da força de trabalho. Considerando que essa força de trabalho será potencialmente utilizada pelo capital para a produção do valor de troca, então podemos caminhar no sentido de desconstruir a falsa ambiguidade entre produção/público e reprodução/privado, para compreender, respeitando suas distinções, a produção dos cuidados como fator elementar que agrega valor à economia capitalista, sem os quais tornaria, no mínimo, profundamente truncado e custoso ao capital a manutenção de capital humano (Carrasco, 2003).

Brito e Oliveira (1998, p. 252) comentam que a divisão sexual do trabalho não cria a subordinação e a desigualdade das mulheres no mercado de trabalho, mas recria uma subordinação que existe também nas outras esferas sociais. Para as autoras,

A divisão sexual do trabalho está inserida na divisão sexual da sociedade com uma evidente articulação entre trabalho de produção e reprodução. E a explicação pelo biológico legitima esta articulação. O mundo da casa, o mundo privado é seu lugar por excelência na sociedade, e a entrada na esfera pública, seja através do trabalho ou de outro tipo de prática social e política, será marcada por esse conjunto de representações do feminino. (Idem)

A divisão sexual do trabalho é construída como prática social, ora conservando tradições que ordenam tarefas masculinas e tarefas femininas na indústria, ora criando modalidades da divisão sexual das tarefas. A subordinação de gênero, a assimetria nas relações de trabalho masculinas e femininas manifesta-se não apenas na divisão de tarefas, mas nos critérios que definem a qualificação das tarefas, nos salários, na disciplina do trabalho. A divisão sexual do trabalho não é tão somente uma consequência da distribuição do trabalho por ramos ou setores de atividade, mas também o princípio organizador da desigualdade no trabalho (Lobo, 1991). 
O tempo de trabalho apresenta-se de forma mais extenuante para mulheres, pois o trabalho doméstico não é determinado pelo mesmo tempo que rege o assalariado. Conforme Hirata e Zarifian (2003), o trabalho doméstico, por manter relação estreita com a noção de afeto, maternidade e família, pressupõe "disponibilidade" integral de quem o exercita, no caso as mulheres, vistas como personagens centrais da vida doméstica. Por não adequar-se à mensuração de tempo que dá a lógica do trabalho assalariado, o trabalho doméstico passa a ser lócus de exploração.

Gênero, classe e raça são categorias coextensivas no dizer de Kergoat (1996), e um nó, no dizer de Saffioti (1992). Essas duas preposições, a nosso ver, se estendem ao gênero e à divisão sexual do trabalho. A divisão sexual do trabalho, como base material do sistema sexogênero concretiza e dá legitimidade às ideologias, representações e imagens de gênero. Estas, por sua vez, fazem o mesmo movimento em relação às práticas cotidianas que segregam as mulheres nas esferas reprodutivas e produtivas, num eterno processo de mediação.

A crescente inserção das mulheres no mercado de trabalho foi um dos fatores que trouxeram novos debates com relação ao trabalho feminino. $\mathrm{O}$ fato de terem salários menores que os dos homens, ou até mesmo dupla jornada, são elementos que aparecem para discussão do lugar assumido pela mulher no mundo do trabalho e que estão relacionados às possibilidades que elas têm de enfrentar riscos sociais e situações de vulnerabilidades provocadas pela situação de pobreza.

\section{0 discurso da feminização da pobreza como caminho para a geração de renda}

Discutir a pobreza feminina requer, primeiramente, retomar o laço que une a perspectiva de gênero às relações sociais. $\mathrm{O}$ conflito entre classes sempre foi discutido sob a perspectiva de duas classes opostas e antagônicas, que protagonizam no cenário social relações de dominação de um sobre o outro. Hirata e Kergoat (1994) chamam a atenção para o cuidado que se deve ter quando utilizamos classe social para tratar as desigualdades sociais. Corre-se o risco de homogeneizar os sujeitos dentro das classes a que pertencem, não colocando 
em evidência outras relações que perpassam e alimentam as relações sociais, como as relações de gênero. As autoras comentam que essas dimensões gênero e classe são coextensivas, como já assinalado nesse texto.

Na realidade, relações de classe e de sexo organizam a totalidade das práticas sociais, em qualquer lugar em que se exerçam. Em outras palavras: não é só em casa que se é oprimida nem só na fábrica que se é explorado (a)! As relações de classe devem, pois, ser analisadas como inculcando conteúdos e orientações concretas nas relações de sexo e, inversamente, as relações de sexo devem ser analisadas como fornecendo conteúdos específicos às outras relações sociais. (Hirata e Kergoat, 1994, p. 96)

Como já salientamos, não podemos nos esquecer de raça/etnia como parte do nó.

Essa abordagem nos ajuda a refletir a respeito da pobreza entre as mulheres. Cabe lembrar que pobreza não é um fator que se manifesta apenas para a classe feminina. No seu conjunto, reflete sobre homens e mulheres, o que nos faz pensar que se trata de um problema estrutural, produto do conflito entre capital e trabalho e que atinge as classes dominadas. Lavinas (apud Novellino, 2004, p. 5) afirma que as mulheres pobres, tal como os homens pobres, representam $25 \%$ da população do seu sexo. Numericamente, portanto, a pobreza entre as mulheres não tem maior expressão que a pobreza entre os homens. Entretanto, as refrações da pobreza são sentidas de maneiras diferentes pelos sexos.

Segundo Melo (2005), quando se trata de pobreza, é essencial o recorte de gênero, uma vez que as condições objetivas de trabalho se apresentam de formas diferentes para ambos, ou seja, a materialização das práticas femininas — historicamente invisíveis quando relacionadas com a esfera produtiva — permanecem subalternizadas, tornando-se um elemento estrutural, o que dificulta ou até mesmo impede o acesso e a permanência em trabalho remunerado.

Para as mulheres, esta realidade de carências é mais aguda, uma vez que elas realizam uma gama enorme de atividades não remuneradas, seja no âmbito mercantil, seja no seio da família, pela dedicação às atividades do lar que as fazem ser majoritariamente dependentes da provisão masculina para o sustento de suas famílias. [...] há uma nítida relação entre divisão do trabalho e a pobreza das mulheres; a inserção feminina aconteceu em paralelo com o crescimento 
das atividades informais, das atividades sem remuneração e aumento das taxas de desemprego. (Melo, 2005, p. 14)

Castro (1999) alerta que o debate sobre a "feminização" da pobreza deve ser visto do prisma crítico, e não das leituras liberais. Reconhecer a vulnerabilidade das mulheres exige a contemplação da discussão da desigualdade de classes, raça/cor/etnia e geração. Agregar tais elementos se faz necessário em decorrência da prática de políticas públicas focalistas e de ações afirmativas. Estas fazem um recorte em públicos-alvos específicos, tal como mulheres pobres, sob a estratégia de minimizar as discriminações por conta de "identidades político-culturais, como o ser mulher, ser negra, ser jovem ou ser mais velha" (Castro, 1999, p. 90).

A autora também chama a atenção para a afirmação de que há maior grau de pobreza entre as mulheres, provocado pelo aumento da chefia familiar e por se acreditar que a falta da figura do provedor masculino seria o fator complicador para o crescimento da pobreza de famílias com esse tipo de arranjo.

Castro (1999) alerta para alguns equívocos que decorrem dessa leitura. Uma delas refere-se à ausência da figura masculina de provedor. Segundo a autora, não se trata da ausência propriamente dita, mas porque em algum momento foram esposas ou companheiras com possibilidades e oportunidades mais reduzidas frente ao mundo do trabalho do que os homens. Neste caso, dentro da perspectiva da divisão sexual dos papéis, as mulheres, em virtude da sua dedicação aos cuidados e a reprodução, ficaram limitadas quanto a qualidade da sua participação no mercado. Tal fato contribuiu, em um momento de perda de uma fonte de renda - seja do marido ou do companheiro - para uma situação de risco maior entre as mulheres nessas condições.

A autora afirma que mesmo que não tenha havido a presença do marido ou companheiro, ou seja, que se trate de mulheres que constituíram família sem a presença de um homem na casa, ainda sim sua posição no mercado se dá mediante a figura de mãe e esposa, e, portanto, o salário é percebido não como fonte principal de renda, mas como rendimento complementar.

Nesta perspectiva, como coloca Melo (2005), os estudos relacionados à pobreza e gênero, que dão enfoque à chefia feminina como fator causador do aumento da pobreza entre as mulheres, tem sofrido críticas. Um aspecto desta- 
cado é que não se abordam o conjunto de situações que se manifestam na unidade familiar, como a presença das famílias extensas, permanência de jovens adultos nas suas famílias, idosos que residem na mesma casa, entre outros fatores, que surgem em decorrência das estratégias que as famílias mobilizam frente às situações de risco.

É importante destacar que a configuração do mercado de trabalho nas décadas de 1980 e 1990 também tem um importante peso para a discussão do aumento da pobreza entre as mulheres.

As mulheres inseridas no mercado de trabalho, assim como os homens, também foram pressionadas pelos rebatimentos da reestruturação produtiva, como desemprego, terceirização e flexibilização dos direitos trabalhistas. Embora tenha havido uma precarização do trabalho de forma geral, para as mulheres esse processo significou uma pressão maior para o trabalho informal, instável e precário, por razões tanto de ordem simbólica — o mito do destino doméstico e reprodutivo, enquanto espaço natural —, quanto de expressão material, relacionadas à pretensa desqualificação das mulheres frente ao novo padrão de acumulação exigente com a máxima qualificação da força produtiva.

Via de regra, as mulheres foram assumindo, não exclusivamente, os trabalhos relacionados com o setor de serviços e com os trabalhos que poderiam ser desempenhados em casa, todos, na sua grande maioria, expressão da insegurança e da precariedade do trabalho.

Neste sentido, como aponta Melo (2005), os fatores que interferem para o aumento da pobreza das mulheres estão vinculados majoritariamente à qualidade da sua inserção no mercado de trabalho, que as colocam em condições inferiores o que reflete na sua sobrevivência. ${ }^{1}$

O trabalho de homens e mulheres, configurados numa estrutura de divisão sexual do trabalho, como já foi dito, sofre os rebatimentos das mudanças ocorridas no mundo do trabalho de formas diferentes. Isto porque clivagens de gênero que interferem na organização do trabalho têm um papel fundamental não só no modo como as mulheres se expressam no mercado de trabalho, mas

1. A mulher como referência na família não pode ser utilizada enquanto única via explicativa no que se refere ao aumento da pobreza entre as mulheres. Há que se considerar também a relação da mulher com o mundo do trabalho, além das transformações econômicas, que afetaram trabalhadores e trabalhadoras na ordem social. 
também no desenho das políticas públicas, que de alguma forma recriam as fronteiras que separam homens e mulheres e invisibilizam estas últimas.

\section{Geração de renda para mulheres no contexto neoliberal}

A ascensão das políticas voltadas para a geração de renda deve ser situada, primeiramente, no contexto histórico que lhe sustenta. O caráter cooperativista e centralizado na organização autônoma do trabalho é facilmente incorporado pelas agendas políticas, principalmente em meados da década de 1990, período de maior consistência para o projeto neoliberal. A estreita relação entre neoliberalismo e os fundamentos das propostas de programas de geração de renda denunciam o caráter político que essa ligação assumiu.

De acordo com Barbosa (2007), a necessidade de redução da participação estatal nos gastos públicos e a centralidade da sociedade civil, combinaram-se ao longo do processo de discussão das políticas públicas voltadas para o trabalho, emprego e geração de renda. As ideias que foram geridas nesse contexto foram de encontro às necessidades peculiares ao projeto neoliberal, e no decorrer da estruturação dessas políticas públicas foram utilizados, orientados por interesses específicos, a fim de transferir a responsabilidade do trato do desemprego para a sociedade civil.

É nesse sentido que a geração de renda assumiu um espaço privilegiado no discurso político do Estado, na possibilidade de criação de estratégias alternativas ao emprego formal e assalariado, e sob o discurso da autogestão e empreendedorismo, mas que serviram tão somente para encobrir a incapacidade política de solucionar ao problema do desemprego.

Assiste-se, assim, a um aumento considerável das políticas que visam a geração de renda tendo como público-alvo mulheres pobres. A construção dessas ações alimenta-se do mercado informal, enquanto meio para a obtenção de renda fora da lógica do trabalho assalariado. Sobre esse assunto, Farah (2004, p. 64), ao analisar programas de geração de renda, comenta:

Os programas de geração de emprego e renda aqui analisados constituem exemplos de focalização de políticas de combate à pobreza. Essa focalização parece decorrer de diversos fatores: Em primeiro lugar, da influência da agenda atual de refor- 
ma das políticas públicas e da tendência de focalização das políticas de combate à pobreza; em segundo lugar, da influência do âmbito local da agenda formulada por movimentos e entidades de mulheres que recomendam que se privilegie o atendimento a mulheres nesse tipo de programa.

A tradução em políticas focalizadas e compensatórias reforçou o caráter da "feminização da pobreza", no sentido mais estrito do conceito, e colocou em pauta, nas agendas públicas, políticas voltadas para mulheres pobres, que caminharam no sentido de "alívio" da pobreza, e não de ações que estivessem também articuladas com o processo de redistribuição de poder entre os sexos. Portanto, a ascensão da agenda de reforma neoliberal contribuiu para abafar muitas das reivindicações surgidas nos movimentos feministas, colocando em xeque as possibilidades para a construção da cidadania e melhora da qualidade de vida das mulheres, em particular das mais pobres (Silveira, 2004).

Assim como apontam Leporace e Fontoura (2004), no eixo das intervenções voltadas para a geração de renda, contempladas no I e II Plano Nacional de Políticas para as Mulheres, foram colocadas algumas diretrizes que deviam caminhar no sentido de promover a independência econômica das mulheres. Alguns dos temas que foram foco das discussões na conferência referem-se à geração de renda, mais especificamente à implementação de políticas de emprego e renda no combate as formas de discriminação baseadas em gênero, raça/etnia e geração, bem como o fomento da promoção da autonomia das mulheres vítimas de violência, por meio de estratégias de geração de renda e trabalho.

A conquista da autonomia econômica, neste sentido, encontra alguns obstáculos. O primeiro deles refere-se ao desenvolvimento de atividades consideradas "femininas" e, que de algum modo, sempre pertenceram ao universo do trabalho doméstico - como já abordado aqui, práticas historicamente invisibilizadas e de baixo valor social. Assim, como coloca Barbosa (2007, p. 119), a cadeia produtiva autônoma encontra-se subsumida ao ritmo e aos ditames do mercado formal, deixando "a margem de autonomia pequena ou inexistente nos casos em que o empreendimento tem viabilidade econômica". O trabalho desenvolvido a partir dos grupos de geração de renda, além de já nascer sob essas condições, ainda conta com um baixo valor agregado, por não ser parte de uma unidade econômica, mas ser responsabilidade maternal e conjugal, comum na relação familiar. 
Outros problemas referem-se à obtenção de microcréditos para início do negócio, na medida em que as garantias exigidas pelas instituições financeiras muitas vezes extrapolam as possibilidades dessas mulheres, bem como a insuficiente análise de viabilidade econômica, refratando as possibilidades de sustentação no mercado. Conforme comenta Yanoulllas (2002, p. 33),

É muito baixa a capacidade de sustentação econômica dessas atividades, com consequente impacto sobre as pessoas que nela se envolvem. Entre as dezenove experiências consideradas inovadoras pelos gestores do plano, constata-se que nenhuma delas está referida a setores de ponta da economia, nenhuma está diretamente relacionada a atividades cujos níveis de desemprego tenham penalizado preferencialmente as mulheres.

As políticas de geração de renda que se pautam por essa perspectiva de intervenção, além de pouco provavelmente conseguirem atingir o pressuposto da conquista de autonomia econômica pelas mulheres, ainda, de acordo com Silveira (2004, p. 68), “consagram e reproduzem a tradicional divisão sexual do trabalho e ignoram um processo de construção da cidadania 'não regulada' que se assenta na visão de sujeitos integrais que circulam nos espaços públicos e privado com autonomia". A autora ainda destaca que é preciso visualizar o contexto socioeconômico em que se opera a inserção da mulher no mercado de trabalho, bem como seus agentes condicionantes, tal como a precarização e os baixos salários, como forma de encarar os limites e as possibilidades de se propor políticas que, de fato, tragam subsídios para a conquista da autonomia econômica.

Para Godinho (2003), a responsabilidade de modificar as desigualdades sociais decorrentes da assimetria das relações de poder entre os sexos cabe ao poder público, através de políticas que incorporem a perspectiva de gênero na sua agenda política. A autonomia no campo econômico tem seu eixo estruturante no trabalho e no emprego, o que, para a autora, fica restrito dentro das possibilidades do município. Entretanto, o mesmo é responsável por políticas que atravessam diretamente o cotidiano dessas mulheres, tais como escolas e creches, que, dada a devida importância, pode possibilitar a liberação do tempo utilizado na vida doméstica, para o desenvolvimento profissional e, consequentemente, a qualificação da presença da mulher no mercado de trabalho. 
Tais políticas, ao mesmo tempo, possibilitam não apenas reduzir a desigualdade por meio da ampliação do acesso a serviços e direitos, mas também estender a responsabilização pública pelo bem-estar dos indivíduos e, neste sentido, rediscutir e colocar em xeque a responsabilidade atribuída às mulheres pela reprodução cotidiana. (Godinho, 2003, p. 60)

Deste modo, a configuração das políticas pautadas na geração de renda, que no projeto neoliberal tem como foco mulheres pobres, incorpora os elementos da divisão sexual do trabalho, ativando estratégias de intervenção que acabam por reproduzir as desigualdades de poder entre os sexos, reforçando ou mantendo padrões que as criam.

Na medida em que são localizadas como referência em suas famílias, essas mulheres serão focalizadas como "gancho" para o desenvolvimento de ações com o objetivo de manter a sobrevivência da família por meio de estratégias que, em uma primeira leitura, aparecem como alternativas paralelas ao mercado. As atividades que na sua maioria, são consideradas de baixo custo de produção e se apoiam em funções como cabeleireira, costureira, doceira, entre outras, remetem à tradicional divisão sexual do trabalho e na sua maioria mantêm as mulheres presas aos domicílios de forma a compatibilizar o trabalho gerador de renda com o trabalho doméstico.

\section{Conclusão}

A partir dessas indagações, questiona-se o impacto da política de geração de renda na vida das mulheres e se coloca em pauta questões como autonomia e empoderamento, termos cuja concepção não é explicitada e nem os instrumentos de avaliação e monitoramento que indiquem que tipo de poder e autonomia são conquistados.

Observa-se que as propostas de geração de renda, no conjunto das medidas neoliberais, são introduzidas para um público predominantemente feminino. São trabalhos manuais, tradicionalmente desempenhados por mulheres no âmbito doméstico e que traduzem os elementos que estruturam a divisão sexual do trabalho.

Não pretendemos aqui afirmar que todos os projetos voltados para a geração de renda para as mulheres são fadados ao fracasso e não promovem nenhum 
tipo de autonomia financeira e certo empoderamento. Há um grande empenho em dar visibilidades aos que deram certo, sendo esses frequentemente retratados em programas televisivos que tratam de empreendedorismo. Mas a maioria não chega a esse patamar, como mostra a pesquisa por nós realizada envolvendo 22 municípios da região. ${ }^{2}$

Por fim, um último ponto refere-se à concepção "geração de renda". Por que quando se trata de mulheres pobres propõem-se geração de renda, e não projetos de capacitação e qualificação para o mercado de trabalho formal? Por que esses projetos, na maioria das vezes, estão na Assistência Social, e não nas instâncias executivas locais responsáveis pelo desenvolvimento e política de trabalho e emprego, como é caso dos municípios de nossa pesquisa?

Em grupos focais realizados para outra pesquisa em andamento, ${ }^{3}$ feitas com mulheres beneficiárias do programa Bolsa Família, elas afirmaram de forma bem objetiva que querem se inserir no mercado formal de trabalho e ter carteira assinada.

As atividades desenvolvidas sob o manto da "geração de renda" ganham em muitos momentos e falas o significado de ocupação de tempo ocioso, tempo que se entende que sobra entre as tarefas intrafamiliares, e não ocupação trabalho como definido no campo da economia. Precisamos ocupar as mulheres?

Artigo recebido em out./2010 aprovado em dez./2010

\section{Referências bibliográficas}

BARBOSA, R. N. C. A economia solidária como política pública: uma tendência de geração de renda e ressignificação do trabalho no Brasil. São Paulo: Cortez, 2007.

BRITO, J.; OLIVEIRA, O. Divisão sexual do trabalho e desigualdade nos espaços de trabalho. In: FILHO, F. S.; JARDIM S. (Orgs.). A danação do trabalho. Rio de Janeiro, Te Corá, 1998.

2. Os dados coletados para a pesquisa "Geração de renda e a perspectiva de gênero", coletou dados de 22 municípios pertencentes à Amuvi — Associação dos Municípios do Vale do Ivaí/PR.

3. "Participação de mulheres em programas condicionados de rendas no Brasil: avanços e contradições para um projeto feminista de empoderamento". 
CARRASCO, C. A sustentabilidade da vida humana: um assunto de mulheres. In: FARIA, Naler; NOBRE, Miriam. Produção do viver. Cadernos SOF, São Paulo, p. 11-49, 2003.

CASTRO, M. G. "Feminização da pobreza" em cenário neoliberal. In: I Conferência Estadual da Mulher. Rio Grande do Sul: Coordenadoria Estadual da Mulher, 1999.

FARAH, M. F. S. Gênero e Políticas Públicas. Revista Estudos Feministas, Florianópolis, v. 12, n. 1, p. 360, jan.-abr. 2004.

GODINHO, T. Construir a igualdade combatendo a discriminação. In: GODINHO, T.; SILVEIRA, M. L. (Orgs.). Políticas públicas e igualdade de gênero. São Paulo: coordenadoria especial da mulher, 2004. 188p. (Cadernos da Coordenadoria Especial da Mulher, 8).

HIRATA, H.; KERGOAT, D. A classe operária tem dois sexos. Revista Estudos Feministas, São Paulo, ano 2, n. 1, p. 93-99, 1994.

HIRATA, H.; ZARIFIAN, P. O conceito de trabalho. In: EMÍLIO, M.; GODINHO, T.; NOBRE, M.; TEIXEIRA, M. (Orgs.). Trabalho e cidadania ativa para as mulheres: desafios para as Políticas Públicas. São Paulo: Coordenadoria Especial da Mulher, 2003. 152p. (Coleção Caderno da Coordenadoria Especial da Mulher, 3).

KERGOAT, D. Relações sociais de sexo e divisão sexual do trabalho. In: LOPES, M. J. M.; MEYER, D. E. E.; WALDOW, V. R. (Orgs.). Gênero e saúde. Porto Alegre: Artes Médicas, 1996.

. Divisão sexual do trabalho e relações sociais de sexo. In: EMÍLIO, M.; GODINHO, T.; NOBRE, M.; TEIXEIRA, M. (Orgs.). Trabalho e cidadania ativa para as mulheres: desafios para as políticas públicas. São Paulo: Coordenadoria Especial da Mulher, 2003. 152p. (Col. Caderno da Coordenadoria Especial da Mulher, n. 3).

KON, A. Considerações teóricas sobre a divisão sexual do trabalho na família: Repercussões sobre o mercado de trabalho. In: SEMINÁRIO AS FAMÍLIAS E AS POLÍTICAS PÚBLICAS NO BRASIL. Belo Horizonte: Abep, nov. 2005.

LEPORACE, M.; FONTOURA, N. Igualdade de gênero no trabalho e a I Conferência Nacional de Políticas para as Mulheres. Mercado de Trabalho, Ipea, 25 nov. 2004.

LOBO, E. S. A classe operária tem dois sexos. São Paulo: Brasiliense, 1991.

MELO, H. P. Gênero e Pobreza no Brasil. Relatório Final do Projeto Governabilidade Democratica de género en America Latina y El Caribe. Brasília: Cepal, 2005. 
NOGUEIRA, C. M. O trabalho feminino e as desigualdades no mundo do Brasil. In: SILVA, M. O. S.; YAZBECK, M. C. (Orgs.). Políticas públicas de trabalho e renda no Brasil Contemporâneo. São Paulo: Cortez; São Luiz: Fapema, 2006.

NOVELLINO. M. S. F. Os estudos sobre a feminização da pobreza e políticas públicas para mulheres. In: XIV ENCONTRO NACIONAL DE ESTUDOS POPULACIONAIS. Minas Gerais: Abep, 2004.

SAFFIOTI, H. I. B. Rearticulando Gênero e Classe Social. In: COSTA, A. O. Uma questão de gênero. Rio de Janeiro: Rosa dos Tempos; São Paulo: Fundação Carlos Chagas, 1992.

SILVEIRA, M. L. Políticas públicas de gênero: impasses e desafios para fortalecer a agenda política na perspectiva da igualdade. In: GODINHO, T.; SILVEIRA, M. L. (Orgs.). Políticas públicas e igualdade de gênero. São Paulo: Coordenadoria Especial da Mulher, 2004. 188p. (Col. Cadernos da Coordenadoria Especial da Mulher, n. 8.)

YANNOULAS, S. C. Dossiê: políticas públicas e relações de gênero no mercado de trabalho. Brasília: CFEMEA, FIG/Cida, 2002. 